\title{
Vantagens Proporcionadas às Pequenas e Médias Empresas por meio da União em Redes de Cooperação no Contexto do Venture Capital
}

\section{Advantages Provided to Small and Medium-sized Enterprises through Cooperation Networking in the Context of Venture Capital}

Patrícia Ross Phonlor

* Endereço: Juliano Machado de Magalhães Rua Santo Ângelo, 97, Bairro Guarani, Novo Hamburgo/RS, 93520-190. E-mail: julianommagalhaes@gmail.com

Copyright @ 2009 RAC. Todos os direitos, inclusive de tradução, são reservados. É permitido citar parte de artigos sem autorização prévia desde que seja identificada a fonte. 


\title{
RESUMO
}

A união de empresas em redes de cooperação surge como estratégia alternativa para enfrentar o aumento da competição proporcionada pela globalização. Diversos autores (Casarotto \& Pires, 1999; Fayard, 2000; Jarillo, 1988; Marcon \& Moinet, 2001) apontam vantagens obtidas por Pequenas e Médias Empresas [PMEs] com o agrupamento em redes. O modelo de investimento de capital de risco aparece como alternativa de união em rede. No Brasil, o venture capital [VC] data dos anos 80; este artigo se propõe a identificar as motivações e vantagens que PMEs obtêm ao se agruparem em rede. Nesse contexto, redes seriam uniões visando à obtenção de vantagens estratégicas. Foram realizadas entrevistas estruturadas com gestores de VC e de empresas aportadas. Os resultados demonstram que a adesão de empresas a este tipo de rede dá-se, inicialmente, em função do custo de capital. Posteriormente, há o reconhecimento de outras vantagens, como trocas de informações, melhoria em processos, expertise para obtenção de financiamento e maior aprendizagem do processo de governança. Concluise que a literatura sobre as vantagens da união em rede aplica-se as VC, apesar de poucos estudos no Brasil abordarem esta relação. Sugere-se, assim, o aprimoramento dos conceitos e vantagens deste tipo de rede para o aprofundamento do tema na academia.

Palavras-chave: capital de risco; redes de cooperação; gestão.

\begin{abstract}
The association of companies in cooperation networks arises as an alternative strategy to cope with the increase of competition brought by globalization. Several authors (Casarotto \& Pires, 1999; Fayard, 2000; Jarillo, 1988; Marcon \& Moinet, 2001) point out the advantages Small and Medium-sized Enterprises [SME] obtain from networking. The venture capital investment model [VC] appears as a networking alternative. In Brazil, VC began in the 80's. Therefore, this article aims to identify the motivations and advantages that SMEs obtain when they join a network. In this context, networking would be aiming at attaining strategic advantages. Structured interviews with VC and appointed companies' managers were conducted. The results have shown that companies' acceptance of this type of networking usually takes place due to capital costs. Later, the advantages are recognized, such as the exchange of information, improved processes, expertise in obtaining financing and the governance process. We conclude that literature on networking advantages applies to VC, although there are only a few studies in Brazil concerning this relationship. Thus, we propose the development of a better understanding of the concepts and advantages of this kind of networking so that this theme can be further studied academically.
\end{abstract}

Key words: venture capital; cooperation networking; management. 


\section{INTRODUÇÃO}

Autores têm sinalizado que as configurações em rede permitem que as Pequenas e Médias Empresas [PME's] obtenham vantagens estratégicas (Casarotto \& Pires, 1999; Fachinelli, Marcon, \& Moinet, 2001; Fayard, 2000; Jarillo, 1988; Marcon \& Moinet, 2001). Dentre estas vantagens possíveis de serem conquistadas, encontra-se maior troca de informações e conhecimento entre empresas, maior participação em vendas de produtos em feiras, lobbying, melhorias em processos empresariais, barganha de preço junto a fornecedores, marketing conjunto, dentre outros. De forma geral, o surgimento de redes de cooperação tornou-se prática comum em diversas indústrias de distintos países, sem restrições de tamanho ou escopo de mercado (Fachinelli et al., 2001).

Apesar das vantagens proporcionadas por redes de cooperação, freqüentemente empresas encontravam barreiras para um crescimento mais vigoroso que a média de suas indústrias, como é o caso da falta de capital para investimentos. Em meados da década de 1940, nos Estados Unidos, empreendedores e investidores desenvolveram uma alternativa para o problema da expansão dos negócios: ficou conhecida como capital de risco, ou venture capital, no inglês. O capital de risco, mais que uma maneira de alavancar e viabilizar empreendimentos por meio da injeção de capital em empresas, nascia como forma de investimento para os detentores de recursos financeiros. Empresas especializadas na gestão de fundos de capital de risco surgiram (Thornton, 1999) e apresentavam-se como a ligação entre investidores e empreendedores. A estes, possibilitou-se a oportunidade de adquirirem experiências, dividirem riscos e recursos. Àqueles, uma forma de melhor remunerar seus recursos.

Por reunirem quantidades e tipos de empresas diferentes sob seu guarda-chuva, as empresas administradoras de capital de risco, juntamente com suas empresas aportadas, configuram-se como um tipo de network que existe nos EUA há mais de meio século e foi responsável pelo surgimento e fomento de empresas hoje consagradas mundialmente, como é o caso da Apple, Intel, Microsoft, Federal Express, Starbucks, entre outras (Bottazzi \& Rin, 2002). O tamanho desse tipo de negócio, segundo Thornton (1999), era de aproximadamente US\$ 10,4 bilhões no fim do ano de 1997.

No Brasil, a história do investimento de capital de risco é mais recente e tem como marco o início da década de 1980, com a atuação de poucas e pequenas empresas. Longos períodos de inflação podem ter-se constituído no entrave principal para o desenvolvimento mais arrojado deste tipo de atividade no Brasil. Passados alguns anos, com o Plano Real de 1994 e a subseqüiente estabilização da economia, a atividade de capital de risco e, conseqüentemente, a união de empresas em redes de cooperação de venture capital, tornou-se um negócio de melhores perspectivas de retorno, tanto para investidores como para empreendedores.

O estudo de redes de cooperação no contexto de empresas unidas por meio do investimento de capital de risco no Brasil mostra-se como um passo relevante para a discussão e aprimoramento dos conceitos sobre este tipo de rede dentro da academia de administração. Tendo este pressuposto em mente, o presente trabalho tem como objetivo verificar e analisar quais são as razões que levam PME's a aderirem à redes de cooperação de venture capital e as vantagens daí advindas. Em outras palavras, o artigo busca responder a duas perguntas: o que leva PME's a optarem por vender parte de seu capital em troca de investimentos de administradoras de capital de risco? E ainda, quais as vantagens da união em rede tanto com a administradora de capital de risco como com demais empresas receptoras de investimento?

Para a obtenção de respostas que contribuam para a investigação do tema, foi apresentada revisão bibliográfica sobre o tema de redes de cooperação e venture capital, estabelecendo, assim, as bases teóricas para a pesquisa de campo. Utiliza-se neste trabalho a metodologia de pesquisa exploratória, por meio de entrevistas estruturadas com diretores e gestores de empresas aportadas com recursos de capital de risco, bem como gestores de empresa administradora de capital de risco, todas estas companhias situadas na região metropolitana de Porto Alegre, Estado do Rio Grande do Sul. 
O artigo está dividido da seguinte forma: a segunda seção apresenta o referencial teórico e conceitos sobre redes de cooperação. Conceitos e vantagens estratégicas advindas da associação em redes de venture capital são apresentadas na terceira seção. A quarta seção descreve o método utilizado no estudo, bem como características básicas das empresas entrevistadas. Ao longo da quinta seção, são apresentadas as análises dos resultados obtidos com as entrevistas estruturadas. Por fim, a sexta seção traz as principais conclusões do trabalho, bem como limitações e sugestões de pesquisas futuras para o aprofundamento do estudo do tema em questão.

\section{Conceitos Centrais sobre Redes de CoOperaçÃo}

A globalização dos mercados e da produção está pondo em questionamento a competitividade das pequenas empresas, restando a estas a tarefa de implementar e reorganizar sua atuação de forma que consigam sobreviver em um mercado progressivamente mais competitivo (Casarotto \& Pires, 1999). Neste contexto, uma forma de diminuir riscos e obter sinergia pode-se traduzir na formação de alianças entre pequenas e médias empresas, pelo fato de estas possuírem maiores dificuldades ou limitações para competirem isoladamente. Através de relações cooperativas, as empresas podem trabalhar conjuntamente para melhorar o desempenho, partilhando recursos e se comprometendo com objetivos comuns (Gnyawali \& Madhaven como citado em Balestro, Lopes, \& Pellegrim, 2004). A configuração em rede também promove ambiente favorável ao compartilhamento de informações, de conhecimentos, de habilidades e de recursos essenciais para os processos de inovação (Balestrin \& Vargas, 2004). Desta forma, empresas podem minimizar suas dificuldades individuais e tornarem-se hábeis em alcançar competitividade nos mercados em que atuam, por meio da adesão a redes de cooperação.

Devido ao seu tamanho, normalmente a pequena empresa apresenta dificuldades para dominar todas as etapas da cadeia de valor. Segundo Porter $(1986,1989)$, identificar apropriadamente as atividades da cadeia de valor de uma empresa é fundamental, para que se enxerguem os seus pontos fracos e fortes, bem como é essencial para a formulação estratégica e obtenção de vantagem competitiva. Porter aponta três possíveis estratégias genéricas que podem ser adotadas por empresas, dentro de um ambiente de competição: custo, diferenciação e enfoque (Porter, 1986, 1989). Geralmente, quando se adota a estratégia de custo, parte-se do pressuposto de que a atividade de uma empresa estará alicerçada em economias de escala, o que, em última análise, pressupõe grandes empresas e altos investimentos. Pequenas empresas, por normalmente não trabalharem com grandes escalas ou não possuírem boa captação de recursos, podem encontrar dificuldades na competição com grandes firmas, focando-se em estratégias baseadas em diferenciação, com produtos ou serviços que se distingam dos oferecidos pela concorrência (Porter, 1986).

Outra estratégia possível para uma PME seria a de enfoque, que se baseia no fato de uma empresa ser capaz de atender melhor ao seu alvo estratégico do que aqueles concorrentes que buscam atender toda a indústria, ou grande número de segmentos da indústria. $\mathrm{O}$ foco, alvo ou escopo estratégico deve ser suficientemente estreito, permitindo que a empresa o atenda de forma mais eficiente e eficaz. Este pode ser definido sob diversas dimensões: tipo de clientes, linha de produtos, variedade do canal de distribuição, área geográfica (Porter, 1986). Assim, analisando as estratégias propostas por Porter, pode-se afirmar que a seleção da estratégia é um fator preponderante para se atingir um patamar de crescimento e prosperidade eficiente para a empresa. Desta forma, complementarmente, a união de PME's em redes vai ao encontro da superação de limitações impostas pela própria cadeia de valor das empresas, bem como pela competição da indústria da qual fazem parte. As redes estratégicas voltamse ao desenvolvimento da capacidade de agir e decidir. Segundo Fachinelli et al. (2001) e Marcon e Moinet (2001), a estratégia-rede supõe compartilhar um projeto que se inscreve em campo de ação. A proximidade territorial, tanto quanto a interdependência econômica, constituem lógicas coerentes de definição do campo de ação de uma rede. Outra característica da estratégia-rede diz respeito à continuidade e convivência. Dentro deste espírito, deve-se gerar uma dinâmica de aprendizagem, que 
pode ser dividida em: aprendizagem de competências e aprendizagem relacional. A aprendizagem de competências diz respeito a conhecimentos e capacidades, enquanto a aprendizagem relacional trata da sociabilidade própria à rede de atores, permitindo que cada membro crie novas soluções para os problemas (Fachinelli et al., 2001; Marcon \& Moinet, 2001) e ainda, que idéias se transformem em ações rapidamente (Uzzi, 1996).

Neste contexto, Paiva e Barbosa (2001) indicaram que as redes são cenários favoráveis para a exploração de oportunidades por parte das pequenas empresas, argumento corroborado posteriormente por Balestrin e Vargas (2003a, 2003b). Jarillo (1988) descreve as redes como sendo acordos de longo prazo, com propósitos claros entre empresas distintas, porém relacionadas, que permitem estabelecer ou sustentar uma vantagem competitiva em face das empresas de fora da rede. Este conceito pode ser considerado o mais adequado ao contexto desta pesquisa; este foi utilizado como base para a seqüência da pesquisa.

Complementarmente, para Ribault, Martinet e Lebidois (1995), a sociedade de empresas, por vezes chamada rede de empresas, é um modo de agrupamento de empresas destinado a favorecer a atividade de cada uma delas sem que estas tenham forçosamente laços financeiros entre si. As empresas em rede complementam-se umas às outras nos planos técnicos (meios produtivos) e comerciais (redes de distribuição) e decidem apoiar-se mutuamente em prioridade. No contexto do capital de risco, a pesquisa de Ribault et al. denota aspectos relevantes, ao destacar as possíveis relações técnicas e comerciais, além da relação financeira que pode ocorrer entre empresas. O conceito exposto por Jarillo (1988) conceitua adequadamente as redes, sendo complementado por Ribault et al. (1995), que indica possíveis formas para ocorrer esta relação.

\section{Tipos e Formas de Redes}

De acordo com a conceituação de Leon (1998), as redes de empresas são formadas inicialmente com o objetivo de reduzir incertezas e riscos, organizando atividades econômicas a partir da coordenação e cooperação entre empresas. Na formação de redes entre pequenas empresas existe a possibilidade de estas configurarem-se como redes flexíveis de pequenas e médias, como clusters de empresas (agrupamentos), ou como redes de cooperação, geralmente como organizações virtuais, ou ainda como as chamadas cadeia de gerenciamento de suprimentos.

Para Casarotto e Pires (1999) nas redes topdown, a pequena empresa pode tornar-se fornecedora de uma empresa-mãe ou, principalmente, subfornecedora. Neste tipo de rede, os fornecedores são altamente dependentes das estratégias da empresa-mãe e possuem pouco ou nenhum poder de influência nos destinos da rede.

Já em uma rede flexível, as empresas unem-se na forma de um consórcio com objetivos que podem abranger formação e valorização do produto, valorização da marca, desenvolvimento de produtos, comercialização, exportações, busca por padrões de qualidade e obtenção de crédito (Casarotto \& Pires, 1999).

Podem ser citadas ainda como outras formas de agrupamento em rede: as joint ventures, as alianças estratégicas, as relações de terceirização e subcontratação, distritos industriais, consórcios, redes sociais, redes de cooperação entre pequenas e médias empresas, entre outras (Grandori \& Soda, 1995; Powell, 1990).

Grandori e Soda (1995), numa compilação de diversos trabalhos, propõem uma nova tipologia denominada "Redes Interempresariais". Esta tipologia visa identificar formas de redes de cooperação em função dos diferentes mecanismos de coordenação empregados e também em função de seus graus de formalização, centralização e mecanismos de cooperação. Dessa forma, as redes empresariais podem apresentar-se como sociais, burocráticas e proprietárias, conforme Tabela 1. 
Tabela 1: Descrição dos Tipos de Redes de Cooperação

\begin{tabular}{|c|c|c|c|}
\hline $\begin{array}{c}\text { Tipo de } \\
\text { Rede }\end{array}$ & Descrição & Simétricas & Assimétricas \\
\hline $\begin{array}{c}\text { Redes } \\
\text { Sociais }\end{array}$ & $\begin{array}{l}\text { Relacionamento dos } \\
\text { integrantes não é regido } \\
\text { por nenhum tipo de } \\
\text { contrato formal. }\end{array}$ & $\begin{array}{l}\text { Não há pólo detentor de } \\
\text { poder diferenciado. Todos } \\
\text { participantes têm a mesma } \\
\text { capacidade de influência. } \\
\text { Exemplos: pólos de P\&D, } \\
\text { distritos de empresas de alta } \\
\text { tecnologia. }\end{array}$ & $\begin{array}{l}\text { Há a presença de um agente } \\
\text { central. São estabelecidos } \\
\text { contratos com relação às } \\
\text { trocas entre empresas e não } \\
\text { sobre a configuração da rede. }\end{array}$ \\
\hline $\begin{array}{l}\text { Redes } \\
\text { Burocráti- } \\
\text { cas }\end{array}$ & $\begin{array}{l}\text { Existência de contrato } \\
\text { formal para reger trocas } \\
\text { comerciais, organização } \\
\text { da rede e } \\
\text { relacionamento de seus } \\
\text { membros. }\end{array}$ & $\begin{array}{c}\text { Exemplos: associações } \\
\text { comerciais, pois auxiliam o } \\
\text { desenvolvimento de acordos } \\
\text { formais de relacionamento } \\
\text { entre diversas firmas de um } \\
\text { mesmo setor, sem que } \\
\text { prevaleçam interesses } \\
\text { individuais. }\end{array}$ & $\begin{array}{c}\text { Exemplos: redes de agências, } \\
\text { licenciamento e franquias. } \\
\text { Contratos com alto grau de } \\
\text { intensidade organizacional, } \\
\text { com cláusulas de } \\
\text { exclusividade, direitos de } \\
\text { inspeção e controle. }\end{array}$ \\
\hline $\begin{array}{l}\text { Redes } \\
\text { Proprietá- } \\
\text { rias }\end{array}$ & $\begin{array}{l}\text { Direitos de propriedade } \\
\text { geralmente estabelecidos } \\
\text { ou cedidos mediante } \\
\text { formalização. Parte de } \\
\text { uma rede burocrática } \\
\text { com adição de } \\
\text { comprometimento com } \\
\text { relação à propriedade. }\end{array}$ & $\begin{array}{l}\text { Exemplos: joint ventures, } \\
\text { que têm sido muito efetivas } \\
\text { na regulação das atividades } \\
\text { de P\&D, em atividades de } \\
\text { inovação e de sistemas de } \\
\text { produção de alto conteúdo } \\
\text { tecnológico. }\end{array}$ & $\begin{array}{c}\text { Exemplos: venture capital, } \\
\text { encontradas com frequiência } \\
\text { nos setores de tecnologia de } \\
\text { ponta. É considerada não } \\
\text { somente uma forma de } \\
\text { financiamento, mas também } \\
\text { uma relação organizacional } \\
\text { entre investidor e firma } \\
\text { aportada. }\end{array}$ \\
\hline
\end{tabular}

Fonte: elaborado com base em Grandori e Soda (1995, pp. 199-205).

\section{Vantagens na Formação de Redes de Cooperação}

Segundo Casarotto e Pires (1999), ao se reunirem em rede, as empresas tornam-se mais competitivas, reduzem custos, podem compartilhar seus recursos de produção e atualizar-se mais rapidamente, conseguindo, desta forma, concentrar seus esforços em atividades nas quais são mais eficientes.

Para Gulati, Nohria e Zaheer (2000), as empresas pertencentes a redes de cooperação têm maior acesso a informações, recursos e tecnologias que contribuem para a vantagem competitiva, bem como o compartilhamento de riscos, outsourcing de cadeias de valor e funções organizacionais.

Já para Human e Provan (1997), as empresas em redes de cooperação realizam trocas no que tange a negócios, informações, inter-relações de amizade e de competências.

A formação de redes de pequenas empresas possibilita a estas um posicionamento estratégico no mercado, como, por exemplo, em uma das três estratégicas genéricas sustentadas por Porter (1986): (i) liderança no custo; (ii) diferenciação; ou (iii) enfoque. Utilizando uma destas estratégias de Porter, uma empresa pode focar-se em baixo custo, operacionalizando a estratégia por meio de alta especialização e conseqüente fornecimento de produtos como sistemista para grandes corporações, como montadoras de automóveis, eletroeletrônicos, eletrodomésticos, dentre outras. Já para uma estratégia de diferenciação, empresas inseridas em um cluster específico podem ofertar produtos com alto grau de customização, como diferencial em relação a seus concorrentes, agregando ainda outros diferenciais, como matérias-primas com nível de qualidade superior ou ofertando tempo de entrega mais rápido que seus concorrentes com produção customizada. Por fim, para uma estratégia de enfoque, uma empresa pode se direcionar a um tipo específico de cliente, produto ou canal de distribuição. 
Considerando a diversidade de formas de redes de empresas, não existe uma regra única no que tange às vantagens de sua constituição. Segundo Ribault et al. (1995), a principal vantagem pode ser apontada como sendo a especialização. As empresas escolhem-se por afinidade, podendo constituir uma rede profundamente original em relação às empresas concorrentes, assim conferindo a si próprias um grau elevado de exclusividade. Exemplos deste tipo de foco em especialização podem ser as empresas que constituem um pólo de tecnologia, estando estas direcionadas para um objetivo: desenvolvimento de novas tecnologias. Existem redes constituídas de empresas com este foco, como a Valetec (2008), Pólo de Informática de São Leopoldo (Universidade do Vale do Rio dos Sinos [Unisinos], 2008), entre outras iniciativas, sendo estas ainda ligadas a um ambiente universitário, conforme o Diário Popular (2005).

Segundo Simantob e Lippi (2003), há muito que aprender com as PME's, pois por estas apresentarem poucas amarras e por serem mais criativas e flexíveis, podem acabar formando cadeias produtivas altamente competitivas, como é o caso, por exemplo, dos clusters de móveis da Itália. Uma das vantagens mais relevantes é que em conjunto, empresas integradas têm mais chances de negociar uma compra com margem superior a uma pequena companhia isoladamente. O Brasil também possui clusters de móveis, estes localizados em regiões distintas no seu território, sendo os principais localizados em: Ubá (MG), Linhares e Colatina (ES), Votuporanga (SP), Arapongas (PR), São Bento do Sul e Rio Negrinho (SC) e Bento Gonçalves (RS) (Gorini, 1998).

No Brasil, segundo pesquisa realizada por Deloitte (2002), as alianças estratégicas foram apontadas como um dos fatores críticos para o crescimento das pequenas e médias empresas que operam no país. Ainda, mesmo na indústria de minério de ferro e siderurgia, setores tradicionais e intimamente relacionados, modificações estruturais têm ocorrido no sentido de estreitar as relações entre os vários atores, mediante a formação de alianças e redes interempresariais.

Existem muitas formas de as empresas se estruturarem em redes, com inúmeras vantagens identificadas em pesquisas e publicações pesquisadas. A Tabela 2 sintetiza as vantagens identificadas no decorrer desta pesquisa.

Tabela 2: Principais Vantagens das Redes de Cooperação

\begin{tabular}{|c|c|}
\hline Maior competitividade & Casarotto e Pires (1999) \\
\hline Menores custos & Casarotto e Pires (1999) \\
\hline $\begin{array}{c}\text { Compartilhamento de recursos de } \\
\text { produção }\end{array}$ & Casarotto e Pires (1999); Gulati et al. (2000); Human e Provan \\
(1997)
\end{tabular}

Fonte: elaborado pelos autores.

\section{EMPRESAS DE VENTURE CAPITAL}

As empresas de capital de risco, ou venture capital como são conhecidas na língua inglesa, surgiram com a necessidade de se fomentar pequenas empresas iniciantes nos EUA, viabilizando aos 
empreendedores a possibilidade de dividirem experiências, riscos e fundos com as chamadas empresas gestoras e investidoras de capital (Thornton, 1999).

A primeira empresa de capital de risco surgiu nos EUA em 1946:

O moderno investimento de capital de risco nasceu em 1946, quando o professor da Universidade de Harvard, Georgios Doriot, criou o chamado American Research and Development [ARD], juntamente com Karl Compton, Merril Griswold e Ralph Flanders, respectivamente presidente do Massachusetts Institute of Technology [MIT], diretor de conselho do Massachusetts Investor Trusts e presidente do Federal Reserve Bank of Boston. ARD levantou fundos junto a indivíduos de posses e universidades e os investiu em empresas de manufatura iniciantes (Bottazzi \& Rin, 2002, p. 233).

Esta iniciativa se desenvolveu em meados do século XX e, após cinqüenta anos, se tornou responsável, ou pelo menos diretamente envolvida, pelo sucesso de grandes empresas norteamericanas. (Bottazzi \& Rin, 2002). Uma iniciativa de pesquisadores e de gestores de instituições financeiras e de pesquisa possibilitou nova forma de compartilhamento de informações e de aporte de capital para empresas ou para idéias que ainda não haviam sido postas em prática. Conforme Bottazzi e Rin (2002), empresas como Apple, Intel, Microsoft, Federal Express e Starbucks foram fomentadas por capital de risco; possivelmente sem isso não teriam obtido o crescimento e o sucesso alcançado. Desta forma, existem pelo menos duas partes envolvidas no negócio do chamado venture capital: o capitalista de risco, também muitas vezes chamado de angel ou anjo, e o empreendedor, dono em grande parte das vezes, de algum diferencial dentro do seu ramo de atuação. Estes atores formam uma rede, constituída pelo anjo e por todas as empresas que recebem investimentos do mesmo capitalista.

Em muitos casos, ocorre a relação entre os diversos agentes, que se organizam em torno do veículo de investimento. Investidores aportam recursos financeiros para um veículo de investimento e, em troca, esperam retornos financeiros condizentes com o risco a que se expõem. Gestores financiam as empresas investidas. Em contrapartida, exigem participação acionária e certos direitos econômicos sobre esta (Gorman \& Sahlman, 1989; Sahlman, 1990).

Para Sahlman (1990) a relação entre investidor e gestor do fundo guarda semelhanças com a relação do gestor e do empreendedor. Certos princípios de governança são comuns ao relacionamento gestor/investidor e gestor/empresa investida: em ambos os casos, os recursos são aportados em etapas, preservando o direito de abandono; enquanto o investidor requer duração limitada do fundo, o gestor exige do empreendedor o atendimento de metas específicas; a forma de remuneração é similar, tanto o gestor quanto o empreendedor possui remuneração com peso maior na componente variável; enquanto o investidor insiste em distribuição anual de lucros, o gestor faz questão de inserir opções de venda, direito de arraste (dragalong) e direito de extensão do prêmio de controle (tag-along) no contrato de compra e venda de ações, garantindo mecanismos de liquidez; nos dois casos, tanto o gestor como o investido sofrem sérias conseqüências, se falharem. Empreendedores ficam sem acesso ao capital e têm sua participação diluída e reputação manchada e gestores malsucedidos dificilmente conseguem levantar novos recursos, pela depreciação da sua reputação.

As empresas aportadas com capitais de risco escapam, freqüentemente, das chamadas barreiras à inovação, como é o caso da inércia verificada em grandes corporações e aversão ao risco presente nos mercados de capitais (Thornton, 1999). Tal vantagem competitiva pode ser em parte atribuída ao fato de que os empreendedores e os capitalistas de risco estabelecem mais do que uma relação de financiamento, de forma que os investidores tomam parte no gerenciamento e desenvolvimento das firmas. Essa característica peculiar faz com que o venture capital lembre muito mais uma estrutura de rede do que uma estrutura hierárquica propriamente dita (Thornton, 1999). De fato, se a relação estabelecida pelo venture capital fosse única e exclusivamente financeira, ou seja, de aporte de capital, os empreendedores buscariam o mercado financeiro e deixariam de lado a opção por entrarem em uma rede de cooperação estabelecida (Grandori \& Soda, 1995).

O diferencial deste tipo de investimento é o suporte gerencial e tecnológico, as relações e as trocas de experiência a que se tem acesso por meio da empresa investidora, aliado a possíveis alianças com 
as outras investidas por ela. Por meio destes diferenciais, a empresa aportada tem acesso ao desenvolvimento de competências organizacionais chave para o seu crescimento.

As relações entre uma investida e uma investidora no capital de risco são muito diferentes da relação tomador de empréstimo e banqueiro, devido ao pacote de expertise ofertado junto ao aporte financeiro. Uma simples operação de crédito não dispõe deste diferencial identificado nas operações de venture capital. Empréstimos bancários são uma solução facilmente utilizável para empresas já estruturadas, com faturamento e histórico de crédito, fato que não é costumeiramente identificado em uma empresa iniciante, como é o padrão das aportadas pelo capital de risco.

A lógica do financiamento através de capital de risco pressupõe o investimento em empresas com expressivo potencial de crescimento, cujo retorno para os investidores possa compensar o alto risco envolvido neste tipo de operação.

Conforme Bygrave e Timmons (1992), a formação da carteira de investimentos reflete a escolha realizada pela empresa de capital de risco. Na prática, esta escolha ocorre na etapa de seleção inicial, quando são descartadas as empresas que não se enquadrarem no perfil desejado.

As escolhas a serem realizadas se referem, segundo Bygrave e Timmons (1992), normalmente, aos casos seguintes.

a) Distribuição setorial da carteira: certa diversificação setorial faz parte das recomendações mais elementares, em termos de estratégia de redução de risco.

b) Distribuição ao longo dos estágios de desenvolvimento: a mesma lógica de diversificação se aplica. A escolha, contudo, em termos da relação risco/retorno, deve levar em conta que as empresas em estágio inicial possibilitam maiores retornos com maiores riscos; o contrário se observa em empresas mais maduras.

c) Outros casos. Outras escolhas podem ser feitas, por exemplo, quanto ao volume dos investimentos ou localização geográfica das empresas, normalmente relacionadas com os altos custos de análise e acompanhamento inerentes às operações destas empresas.

Nos Estados Unidos da América [EUA] este tipo de rede cresceu, em termos de volume de investimentos realizados, 4,1 bilhões de dólares em 1992 para 10,4 bilhões de dólares em 1997, representando um crescimento de $158 \%$. O total de empresas aportadas saltou de $952 \mathrm{em} 1992$ para 2.429 em 1997 (Thornton, 1999). Tal é a importância do venture capital nos EUA que, antes mesmo deste elevado crescimento, o governo americano já participava ativamente em 17 programas estatais de venture capital no ano de 1990 (Leicht \& Jenkins, 1998).

No Brasil, mais especificamente, no ano de 2003, 54 empresas receberam o equivalente a R\$1.308 milhões, ao passo que no ano anterior (2002) foram 79 empresas aportadas e um total de R\$1.211 milhões. O perfil dos investimentos varia; porém há uma clara evidência de que as empresas de tecnologia não estão mais no centro dos investimentos de capital de risco. No ano de 2003, as empresas não-tecnológicas receberam $86 \%$ dos investimentos, o que demonstra uma cautela dos investidores com relação às empresas de tecnologia (Associação Brasileira de Capital de Risco [ABCR] \& Thompson Venture Economics, 2006).

\section{Os Estágios de Investimento do Venture Capital}

Os volumes investidos dentro do segmento de capital de risco são aportados segundo critérios preestabelecidos pelos investidores. De forma geral, o aporte de capital de risco apresenta quatro momentos distintos nos quais pode ser integralizado. A Tabela 3 apresenta os quatro distintos estágios, segundo Bottazzi e Rin (2002). 
Tabela 3: Estágios de Aporte de Capital de Risco: Descrição e Objetivos

\begin{tabular}{|c|c|l|l|}
\hline Estágios & Do inglês & \multicolumn{1}{c|}{$\begin{array}{c}\text { Contribuição do capitalista de } \\
\text { risco. }\end{array}$} & \multicolumn{1}{c|}{ Objetivos } \\
\hline $\begin{array}{c}\text { Semente } \\
\text { financeira }\end{array}$ & Seed Finance & Investimento pequeno. & $\begin{array}{l}\text { Para que o empreendedor verifique } \\
\text { a viabilidade de seu negócio. }\end{array}$ \\
\hline $\begin{array}{c}\text { Financiamento } \\
\text { Inicial }\end{array}$ & $\begin{array}{c}\text { Start-up } \\
\text { Finance }\end{array}$ & $\begin{array}{l}\text { Pode auxiliar com organização e } \\
\text { estratégia corporativa da empresa } \\
\text { aportada. }\end{array}$ & $\begin{array}{l}\text { Investimento para viabar } \\
\text { operações da empresa, contratação } \\
\text { de executivos }\end{array}$ \\
\hline $\begin{array}{c}\text { Expansão } \\
\text { Financeira }\end{array}$ & $\begin{array}{c}\text { Expansion } \\
\text { Finance }\end{array}$ & $\begin{array}{l}\text { Indicação de fornecedores, clientes, } \\
\text { entre outras. }\end{array}$ & $\begin{array}{l}\text { Alcançar produção em escala } \\
\text { industrial, por meio de ampliação de } \\
\text { plantas novas contratações. }\end{array}$ \\
\hline $\begin{array}{c}\text { Estágio } \\
\text { Financiamento } \\
\text { Posterior }\end{array}$ & $\begin{array}{c}\text { Later Stage } \\
\text { Finance }\end{array}$ & $\begin{array}{l}\text { Atuam diretamente no lançamento um } \\
\text { dos papéis na bolsa de valores. }\end{array}$ & $\begin{array}{l}\text { Alcançar liderança de } \\
\text { determinado segmento de mercado, } \\
\text { assim como viabilizar abertura de } \\
\text { capital em bolsa de valores. }\end{array}$ \\
\hline
\end{tabular}

Fonte: elaborado a partir de Bottazzi e Rin (2002, p. 240).

Uma vez consideradas as origens da atividade de capital de risco, suas peculiaridades e seus diversos estágios, conclui-se que a idéia de que venture capital é mais que simples sistema de financiamento; é um tipo de rede. Desta forma, convêm dissertar a respeito das vantagens apresentadas na literatura para aquelas empresas ligadas em uma rede de cooperação de venture capital.

\section{Como Opera um Investidor de Venture Capital e o que Espera da Empresa Aportada}

Inicialmente uma empresa de capital de risco recebe mais pedidos de financiamento do que ela poderia apoiar ou gostaria de apoiar. Por este motivo, é necessária uma seleção prévia ou inicial das propostas, separando-se as empresas que serão objeto de uma análise mais profunda posteriormente. Alguns critérios rápidos e abrangentes são ordinariamente utilizados para uma seleção inicial, refletindo, em parte, a estratégia de investimento do investidor (Sagari \& Guidotti, 1992).

Após esta análise inicial, são submetidos a um processo de análise, em que todos os aspectos e detalhes do investimento proposto são cuidadosamente revistos. O resultado deste processo é a decisão final sobre o investimento, que costuma analisar o plano de negócios, além de aspectos mais concretos, utilizando-se de profissionais com experiência no setor, além de um contador e de um advogado. Entre os aspectos analisados, estão: as qualidades do empresário e de sua equipe, incluindo comprometimento, vontade, honestidade, reputação e criatividade; as características do produto, incluindo preço, forma de distribuição, avaliação da vantagem competitiva; a tecnologia a ser empregada e sua vulnerabilidade; e o potencial do mercado (Sagari \& Guidotti, 1992).

Depois de decidido o investimento, a etapa seguinte é a estruturação da operação. Nesta etapa são definidos os acordos entre a empresa investida e a empresa de capital de risco, nos quais são descritos os direitos e deveres de cada um, com o objetivo de conciliar suas diferentes necessidades, interesses e preocupações.

Vencidas estas etapas de análise, Schilitt (1997) indica que o capitalista de risco aporta à empresa, passa a auxiliar na gestão administrativa e financeira, na definição de estratégias e no recrutamento da equipe de administradores. Para Sagari e Guidotti (1992) este acompanhamento é necessário, porque, ao contrário do financiamento tradicional, a relação entre a empresa capitalista e a empresa investida é de sociedade, de forma que o sucesso do investimento está diretamente relacionado ao desempenho futuro geral da empresa, e não apenas à sua capacidade de gerar fluxos de caixa positivos para o pagamento de obrigações. O objetivo deste envolvimento é evitar perdas e maximizar ganhos para os investidores, mediante da antecipação de possíveis problemas.

Agregando experiência em gestão ao empreendimento recém-constituído, o capitalista de risco contribui para ampliar o potencial de sucesso do novo negócio. Porém a atividade empresarial sempre 
envolve risco e a busca de retorno correspondente ao grau de risco percebido pelo investidor. Um investidor espera que a empresa investida prospere e, com isto, consiga obter maior valor para o seu dinheiro investido, no momento em que for desinvestir o seu capital (Schilitt, 1997).

O período médio de permanência dos investimentos em capital de risco varia de três a sete anos, onde o capitalista de risco espera realizar seus ganhos, seja pela a oferta pública inicial de ações (IPO, na sigla em inglês), seja mediante a venda da empresa para uma concorrente.

Neste contexto, Schilitt (1997) indica que uma carteira típica de um capitalista de risco é composta de $10 \%$ a $20 \%$ de investimentos em empresas com grande potencial de crescimento e sucesso, 30 a $40 \%$ de investimentos em empresas que podem ser medianamente bem-sucedidas e o restante em empresas que apresentam grande probabilidade de perda ou mesmo de total insucesso. Os empreendimentos de alto retorno devem contrabalançar os investimentos com maior probabilidade de insucesso.

\section{Vantagens e Desvantagens na Formação de Redes de Cooperação de Venture Capital}

A literatura encontrada sobre as venture capital possui foco dividido entre as vantagens obtidas pelo investidor e as obtidas pelo receptor cooperado que obtém o investimento da empresa de venture capital.

Sorenson e Toby (2001) indicam que as principais vantagens obtidas neste tipo de rede estão ligadas ao ganho de experiência pelo investido, ao monitorar seus investimentos e no desenvolvimento de competências em atividades como redação de contratos efetivos para minimizar problemas ligados à atividade desenvolvida pela empresa, entre outros. Gompers e Lerner (1998) indicam como grande vantagem a ser obtida pelos investidos o fato de que grande parte das empresas que buscam investimento possui características próprias intangíveis, fato que dificulta a visualização do real valor do negócio e a sua perspectiva de ganho. Porém possibilitam aos investidores a obtenção de maiores ganhos, devido a esta intangibilidade do negócio. Por estes motivos, muitas empresas buscam investimentos de venture capital, pois dificilmente conseguiriam obter financiamentos em instituições bancárias tradicionais, devido a estas características dos seus negócios. Para o investidor um ponto relevante para a decisão de investir neste tipo de empresas seria a possibilidade de diversificação da carteira de investimentos, além do ganho em diluição do risco assumido.

Como desvantagens, a principal para o investidor seria a empresa não rentabilizar conforme o esperado ou, em caso extremo, decretar falência, comprometendo o investimento realizado. Este ponto pode ser evitado com análises minuciosas no momento da seleção do investimento e um acompanhamento de perto das ações dos gestores da empresa investida. Outra desvantagem seriam os possíveis prejuízos por análises mal realizadas ou riscos mensurados de forma inadequada. Por fim, o alto custo para se lançar ações é um empecilho para se desinvestir no contexto do capital de risco.

Autores como Gompers e Lerner (2001) também apontam vantagens - além do aporte de capital possivelmente obtidas por empresas que recebem investimentos de empresas de venture capital, quais sejam: investimento em estratégia, pesquisa, ou projetos que tenham alto retorno pessoal, mas baixa expectativa de retorno financeiro para os acionistas. Pandey et al. (2003) busca conectar as vantagens das empresas aportadas por recursos financeiros em relação às obtidas pelos respectivos empreendedores. Estas vantagens podem estar relacionadas ao desejo de o empreendedor ser responsável pelo seu próprio futuro. As decisões relevantes para a empresa devem ser compartilhadas com investidor, de forma que a gestão é independente até certo ponto, onde a velocidade das decisões acaba por ficar um tanto limitada.

A Tabela 4 apresenta um resumo, esquematizando as vantagens e as desvantagens para os dois principais envolvidos nesta relação: o investidor e o aportado pelo capital de risco. 
Tabela 4: Vantagens e Desvantagens do Capital de Risco

\begin{tabular}{|c|c|c|c|}
\hline & Vantagens & Desvantagens & Autores \\
\hline Investidor & $\begin{array}{l}\text { - maiores ganhos devido a esta } \\
\text { intangibilidade do negócio } \\
\text { - possibilidade de diversificação da } \\
\text { carteira de investimentos } \\
\text { - diluição do risco }\end{array}$ & $\begin{array}{l}\text { - difícil visualização do real valor } \\
\text { do negócio e a sua perspectiva de } \\
\text { ganho } \\
\text { - possíveis prejuízos por análises } \\
\text { mal realizadas ou riscos } \\
\text { mensurados inadequadamente } \\
\text { - alto custo para se lançar ações } \\
\text { (opção de desinvestimento) }\end{array}$ & $\begin{array}{c}\text { Gompers e Lerner } \\
\text { (1998) } \\
\text { Sorenson e Toby } \\
(2001)\end{array}$ \\
\hline Investido & $\begin{array}{c}\text { - ganho de experiência ao monitorar } \\
\text { seus investimentos } \\
\text { - desenvolvimento de competências } \\
\text { em atividades como redação de } \\
\text { contratos } \\
\text { - difícil visualização do real valor do } \\
\text { negócio por parte do investidor e a } \\
\text { sua perspectiva de ganho } \\
\text { - investimento em estratégia, } \\
\text { pesquisa ou projetos específicos } \\
\text { - ser responsável pelo seu próprio } \\
\text { futuro }\end{array}$ & $\begin{array}{c}\text { - custo do capital maior, no caso } \\
\text { do negócio ser rentável, do que se } \\
\text { tivesse obtido financiamento } \\
\text { bancário } \\
\text { - decisões relevantes para a } \\
\text { empresa devem ser } \\
\text { compartilhadas com investidor } \\
\text { (velocidade das decisões fica } \\
\text { limitada) }\end{array}$ & $\begin{array}{c}\text { Gompers e Lerner } \\
\text { (1998) } \\
\text { Pandey et al. } \\
\text { (2003) } \\
\text { Sorenson e Toby } \\
\text { (2001) }\end{array}$ \\
\hline
\end{tabular}

Fonte: elaborado pelos autores.

\section{Contexto da Pesquisa}

Grandori e Soda (1995) afirmam que o investimento de capital de risco é mais que um simples tipo de financiamento; é rede de cooperação formada pelo investidor e pelo aportado. Esta afirmativa é sustentada pelas relações de troca que ocorrem entre a empresa investida e a investidora. Ocorrem trocas de experiências entre as empresas, possibilitando aprendizados para ambas as partes. A relação estabelecida a partir do aporte inicial leva o investidor a ser ativo atuante na busca pelo sucesso do empreendimento aportado.

Uma rede de cooperação de venture capital é constituída, em uma primeira instância por dois atores principais: o investidor de capital de risco e a empresa aportada com recursos. Em um segundo momento, tem-se um grupo maior de atores, composto pela empresa investidora e por todas aquelas empresas que fazem parte do portfólio de investimentos da referida empresa investidora.

Desta forma, busca-se estabelecer um ambiente onde se tem um investidor à procura de investimentos que tornem sua carteira rentável e empreendedores, geralmente executivos de empresas emergentes, que buscam formas de viabilizar o crescimento de suas empresas. As companhias de capital de risco no Brasil trabalham, geralmente, com a constituição e administração de fundos de investimento de capital de risco. A constituição seria a captação de recursos e a administração passa pela identificação de empresas com necessidade de aporte financeiro, seleção do investidos, manutenção da carteira e tem o ciclo finalizado pelo desinvestimento do capital do fundo.

Uma vez dispondo dos recursos para investimento, as empresas investidoras - ou administradoras do fundo de capital de risco - procuram em regiões específicas (em função do foco que o fundo de investimentos tem) empresas emergentes que, baseadas em seus conhecimentos de mercado e estudos desenvolvidos podem oferecer possíveis ganhos diferenciados aos cotistas dos fundos de investimento $\mathrm{e}$, conseqüentemente, para ela própria, a administradora do fundo.

Assim que um acordo é estabelecido e se procede com o aporte de recursos, a forma de investimento na empresa é definida caso a caso. Em algumas situações, a empresa investidora subscreve debêntures passíveis de serem convertidas em ações; em outras, a empresa administradora do fundo de capital de risco entra diretamente como sócia na empresa investida. 
Conforme o próprio testemunho dos profissionais entrevistados que trabalham na companhia administradora de fundos de capital de risco, a atividade de venture capital no Brasil passou por períodos conturbados, levando-se em conta os diversos planos econômicos aos quais a economia brasileira foi submetida. Segundo eles, tornou-se de certa forma um tanto complexo mensurar os reais ganhos, dados aspectos como os já referidos planos econômicos e a inflação, inerente ao cenário econômico brasileiro do passado.

\section{MÉTODO}

A presente pesquisa é de natureza exploratória, já que, segundo Tripodi, Fellin e Meyer (1981), permite ao pesquisador aumentar a experiência em torno de um determinado fenômeno e desenvolver idéias e hipóteses sobre objeto estudado.

Primeiramente se realizou a revisão da literatura sobre o tema Redes de Cooperação e empresas de venture capital, abordando principalmente as vantagens encontradas na formação das redes de cooperação de pequenas e médias empresas e venture capital's.

O método de coleta de dados utilizado foi o de entrevista em profundidade (Hair, Babin, Money, \& Samouel, 2005), aplicada junto aos diretores executivos das duas empresas que receberam aporte de capital de risco, procurando-se captar as percepções deles em face da estratégia de rede, identificando vantagens e desvantagens percebidas ao participarem de uma rede venture capital. A delimitação da coleta de dados inclui duas empresas investidas e seus devidos gestores, além do gestor e o analista de investimento da empresa investidora, totalizando quatro pessoas entrevistadas. Oppenheim (1994) revela que a proposta de entrevistas exploratórias é essencialmente heurística e sua utilização auxilia no desenvolvimento de idéias, na formulação de hipóteses, na coleta de fatos e estatísticas. As entrevistas em profundidade foram gravadas e tão logo concluídas, transcritas com a devida permissão dos entrevistados. A transcrição das entrevistas foi revisada pelos pesquisadores constituindo-se em objetos de análise. Cada entrevista durou em média 60 minutos e seu roteiro de entrevistas foi baseado na revisão da literatura realizada.

Para fins de análise dos resultados e referências às empresas e profissionais que forneceram as informações para este artigo, se tratará a empresa investidora de capital de risco como Investidora e seu gerente de investimentos e analista de investimentos, simplesmente como Investidor 1 e Investidor 2, respectivamente. Com relação às duas empresas que receberam investimentos e que tiveram seus diretores entrevistados, se tratará como Empresa Investida 1 e Empreendedor 1 e Empresa Investida 2 e Empreendedor 2.

A Investidora constitui-se em uma das pioneiras dentro da atividade de capital de risco no Brasil. Iniciou suas atividades no início da década de 1980 e já trabalhou com fundo de capital de risco próprio e outros fundos constituídos com recursos próprios e de terceiros. Cada fundo constituído a partir de 1994 - na correção da inflação - tem um foco específico, bem como uma região específica de atuação, geralmente designado por Estados da federação. Até o presente momento, a empresa já conta com empresas investidas nos Estados do Rio Grande do Sul, Santa Catarina, Paraná e São Paulo.

As Empresas Investida 1 e Empresa Investida 2 constituem-se em duas empresas que receberam aporte da Investidora ao longo dos últimos anos e que têm o Estado do Rio Grande do Sul como origem. Ambas as empresas atuam no desenvolvimento de soluções tecnológicas, sendo a primeira focada em softwares de ERP para a integração da cadeia logística e de suprimentos da indústria calçadista e a segunda atua na construção de portais corporativos, intranets e ainda como gestora do conhecimento por meio de portal corporativo. As duas organizações vendem seus produtos e serviços a empresas brasileiras de grande porte. 
A Empresa Investida 1 possui como principais mercados os clusters calçadistas brasileiros, como o do Vale dos Sinos e o do interior paulista, em cidades como Franca e Birigui. Já a Empresa Investida 2 possui três escritórios em regiões distintas do Brasil: Porto Alegre, São Paulo e Brasília. Esta tem como foco as 1.000 maiores empresas brasileiras do ranking da Revista Exame, segundo relato obtido na entrevista realizada.

A análise dos dados coletados foi um dos momentos mais complexos da construção deste trabalho, pois foi preciso destacar e separar todas as informações coletadas, ressaltando-se os aspectos mais relevantes, esclarecendo as posições assumidas pelos entrevistados. A partir do contato e da coleta dos dados junto às empresas estudadas, se pôde confrontar a construção teórica desenvolvida com a situação verificada nas empresas analisadas.

\section{DESCRIÇÃo do CASO E ANÁlISE dos Resultados}

Esta seção tem como objetivo a análise das informações obtidas por meio das entrevistas estruturadas realizadas junto às empresas entrevistadas. Por meio destes dados, buscou-se obter junto aos entrevistados as vantagens que PME's obtém, quando se unem a uma rede do tipo venture capital. A abordagem deu-se a partir de entrevista feita com a Investidora, obtendo-se, assim, a visão do lado investidor, ou seja, da empresa que administra o recurso do capital de risco como forma de buscar melhor remuneração para o seu capital. Em seguida, são discutidas informações levantadas junto a duas empresas que receberam aporte de capital, buscando-se, assim, contribuições com base na visão dos empreendedores sobre as vantagens obtidas na associação em redes de cooperação de venture capital.

Por meio da entrevista em profundidade aplicada junto aos profissionais da Investidora, obteve-se uma visão do perfil do negócio de capital de risco no Brasil. Quando questionados sobre suas visões a respeito do negócio de capital de risco no Brasil, tanto o Investidor 1, como o Investidor 2 concordaram que "ainda há muita desinformação sobre venture capital no Brasil" e que o Brasil dos dias atuais passa por uma transição de "uma sociedade paternalista para uma geração mais disposta ao entendimento de novos conceitos". Estas afirmações podem vir a fundamentar o entendimento de um caráter ainda incipiente deste modelo de negócios, bem como seu desenvolvimento ainda em curso no Brasil.

Quando perguntados sobre o modo como o negócio de capital de risco é visto, tanto da ótica do investidor como da ótica de quem recebe recursos, Investidor 1 colocou que "o capital de risco exerce papel muito prático onde o custo do capital é o que ainda define a opção por parte do empreendedor". O Investidor 1 completou a linha de pensamento, argumentando que "o venture capital é mais interessante, quando a empresa é pequena" e que "à medida que o negócio aumenta, o empreendedor faz a conta do custo do dinheiro captado e pesa as possíveis diversas formas de obtenção deste retorno". Esta resposta aponta uma tendência de que, em um primeiro momento, um empreendedor busca somente o recurso financeiro que alavanque seu negócio e não demais vantagens que poderiam ser advindas de uma união por meio de uma rede de capital de risco.

Após ter-se obtido um panorama do modo como o negócio de capital de risco é considerado dentro da visão da Investidora, o objetivo passa a ser a identificação de qual é a visão de profissionais da área com relação à atividade de capital de risco e ao conceito de redes de cooperação. Para tanto, foram apresentadas tanto para o Investidor 1 como para o Investidor 2 três definições sobre o conceito de redes de cooperação:

. "Uma resposta estratégica para elevar a capacidade inovativa das empresas" (Balestro et al., 2004, p. $182)$

“objetivos de vantagens mútuas advindas de tal união [em rede de cooperação]” (Ebers, 1997, p. 16); 
"Uma rede de cooperação é um modo de regulação de interdependência entre firmas" (Grandori \& Soda, 1995, p. 184).

Em seguida, formulou-se a seguinte pergunta: "Você considera a relação estabelecida entre Investidora e as empresas investidas uma forma de rede de cooperação?"

Tanto Investidor 1 como Investidor 2 apresentarem alinhamento com relação ao fato de que a relação estabelecida constitui-se em um tipo de rede de cooperação. Imediatamente após a obtenção da resposta positiva, realizou-se outra pergunta, com o intuito de identificar a visão dos investidores em relação às vantagens que as empresas aportadas podem obter desta relação: "Quais as vantagens proporcionadas às PME's investidas pelo relacionamento estabelecido com a Investidora?"

Obtiveram-se como resposta cinco principais vantagens advindas de tal união: (1) obter visão pragmática e fria do negócio, que poderia traduzir-se como uma visão estratégica do negócio, via definição de objetivos e planejamento de médio e longo prazo; (2) metas e ações mais objetivas para a melhoria da rentabilidade da empresa aportada; (3) a experiência agregada por meio de outras empresas da rede de empresas investidas pode gerar ganhos em novos negócios ou mesmo em parcerias; (4) acesso mais fácil a financiamentos - a investidora possui maior grau de conhecimento de possíveis canais para captação de recursos; (5) apresentação e inserção de novas ferramentas administrativas, que venham a possibilitar melhorias e maior controle em processos produtivos, gestão de pessoas, finanças etc.

As vantagens acima mencionadas pelos entrevistados alinham-se com vantagens citadas e descritas em algumas bibliografias pesquisadas. Gulati et al. (2000) afirmam que empresas pertencentes às redes de cooperação possuem maior acesso à informações e, portanto, maior facilidade para a obtenção de investimentos. Isso também foi colocado pelos entrevistados e pode encontrar fundamentação no fato de que, em redes de cooperação de capital de risco, empresas aportadas acabam ampliando suas oportunidades de captação, via maior contato com Bancos de Desenvolvimento Nacionais e Internacionais, acesso este trazido, geralmente, pelas empresas administradoras. Adicionalmente, Human e Provan (1997) afirmam que as empresas realizam trocas de informações, negócios e amizades entre o grupo de empresas participantes de uma rede.

A inserção de novas ferramentas administrativas proporcionou ganho, ao se qualificar processos produtivos, gestão de pessoas e de finanças. A inserção passou por reuniões focadas em apresentar formas mais atuais e reconhecidas em nível de mercado para os processos de gestão. Em alguns casos foram contratados consultores para gerir a modernização destes processos. Houve resistência interna nas empresas investidas, como é de costume em mudanças de gestão empresarial; porém os resultados proporcionaram ganhos em clareza nos processos e maior eficiência, desburocratizando alguns processos e outros tornando-os efetivamente formalizados, no caso de não possuírem rotinas claramente estabelecidas.

O caso dos processos de contratação é um exemplo que torna visível a melhoria do processo anterior, que não contemplava critérios claros nem um processo de contratação calcado em entrevistas realizadas por profissionais qualificados a exercer a função. Foi introduzida uma metodologia sustentada em definição de critérios e capacidades para o contratado, anúncio em agências ou jornais e um processo de entrevistas e dinâmicas aplicadas por profissional contratado para esta função pontualmente.

No tocante aos processos financeiros, foram criadas tabelas para controle de gastos e investimentos, aspecto que antes não era claramente gerido, sendo somente utilizado o livro caixa para esta gestão. Em um segundo momento foi introduzido nas empresas software específico para a gestão do negócio, contemplando módulo financeiro, de pessoas, vendas, compras, entre outros.

Os processos produtivos foram qualificados por meio de reuniões entre investidora e investida, onde se realizavam rodadas de reuniões com outros investidos, visando à troca de experiências e à busca de sugestões e soluções mais adequadas a cada caso. 
Ainda do lado dos empreendedores, a lista que estes fizeram sobre as vantagens e desvantagens, por estarem inseridos no contexto de redes de cooperação de capital de risco, pode ser sintetizada na questão do acesso ao capital.

Dificuldades freqüentemente impostas à obtenção de crédito, como garantias, tamanho do negócio, histórico da empresa e de seus sócios, associadas a taxas de juros tradicionalmente e relativamente mais elevadas que no exterior, por exemplo, acabam levando empreendedores a considerarem outras formas de alavancagem de seus negócios. Em conformidade com o indicado pelos entrevistados da empresa Investidora e dos entrevistados das empresas Investidas, pode-se sugerir que o empréstimo de capital para empresas de pequeno porte exige um nível de documentação muitas vezes inviável de ser levantado, o que, em última análise, traduz-se em uma ferramenta dos agentes financeiros para dirimir o risco de retorno de seus recursos. Para os empreendedores de pequeno porte, surge uma lógica: recursos mais fáceis de serem obtidos em face das oportunidades de risco mais elevado. Justifica-se isso pelo fato de, na atividade de capital de risco, empreendedores venderem parte de seus negócios às investidoras em troca de recursos necessários à expansão de seus negócios.

Por outro lado, empresas de maior porte, com maior capacidade de endividamento, acabam escapando de muitas das barreiras impostas aos pequenos empreendedores para a obtenção de recursos. Uma destas barreiras, conforme apontado pelas entrevistas, traduz-se no prazo de pagamento dos empréstimos, que é geralmente mais apertado para pequenas empresas.

Nessa linha, venture capital surge como alternativa para pequenos empreendedores. Por meio do que é concebido como a atividade de capital de risco, o investidor aporta recursos para um pequeno empreendedor, em troca de cotas da empresa. $\mathrm{O}$ empreendedor geralmente permanece à frente dos negócios, mas fica sujeito a cláusulas de tag along e drag along que podem obrigá-lo juridicamente a vender suas cotas, caso o investidor tenha em mãos oportunidade ímpar para a negociação de toda a empresa.

Outra questão relevante obtida com as entrevistas gira em torno do fato de as duas empresas pesquisadas demonstrarem tendência a receber abertamente sugestões e novas ferramentas gerenciais ofertadas pela empresa Investidora. Este aspecto foi considerado como vantagem pela empresa Investidora e concomitantemente pelas empresas investidas, fato que possibilita a estas o crescimento e a geração de valor, tanto para si quanto para a investidora, que visa obter o máximo retorno sobre o seu investimento. Para maximizar o seu lucro, a Investidora utiliza seu conhecimento e apresenta tecnologias de gestão diferenciadas visando tornar mais clara a operação do negócio. Para apresentar estas possíveis colaborações gerenciais a Investidora disponibiliza o seu corpo técnico, para prestar uma espécie de consultoria e, ainda, proporciona seminários periódicos entre os presidentes das empresas aportadas, visando à troca de experiências e abrindo novas portas para o possível crescimento das empresas investidas.

Pôde-se verificar que a empresa Investidora e as Investidas estudadas necessitam de sinergia entre a visão do empreendedor, que possui um foco específico na atividade desenvolvida pela sua empresa, e a visão externa ao negócio, O empreendedor Investido busca defender seus ideais e sua metodologia pré-existente de trabalho. O Investidor necessita que o empresário apresente as informações da maneira mais clara e objetiva para que os dados referentes ao desempenho da empresa fiquem evidentes e, dessa forma, não sejam omitidas informações que possam demonstrar possíveis tendências de redução ou aumento no faturamento ou mesmo de possíveis instabilidades no fluxo de caixa das empresas.

As empresas Investidas afirmaram necessitar de maior volume de negócios entre as empresas integrantes da rede de cooperação horizontal formada pelos aportados e pela empresa Investidora. A relação horizontal fica clara pela troca de informações e colaboração entre diversas empresas Investidas dentro da rede. É importante ressaltar, entretanto, que ocorrem inúmeras trocas de informações relativas à forma de operar as empresas; porém poucas parcerias se efetivam, tanto em projetos específicos, como em orçamentos conjuntos. Conforme indicado nas entrevistas, a cooperação 
Interempresarial vertical ocorre através da troca de informações e da colaboração entre Investidor e Investidas.

Conclusivamente, foi possível observar que a rede de venture capital apresenta algumas características gerais como:

. Constituída por pequenas e médias empresas;

. Empresas inseridas na área de tecnologia e inovação;

. Os investidores mantêm contato direto com as empresas investidas;

. Os investimentos, em sua maioria, ocorrem em função do custo de capital.

Segundo essas características e as orientações de Human e Provan (1997) e Fachinelli et al. (2001), pode-se conceituar a rede de cooperação de capital de risco como sendo uma rede horizontal. As redes horizontais são formadas por pequenas e médias empresas com a finalidade de trabalhar coletivamente para alcançar objetivos estratégicos comuns (crescimento acelerado, por exemplo), que isoladamente não conseguiriam. A Tabela 5 sintetiza os benefícios propostos nas referências bibliográficas com as evidências empíricas proporcionadas pela pesquisa do presente trabalho, constituindo um elo entre a realidade do venture capital no exterior (grande parte das bibliografias sobre o assunto é de fora do Brasil) com a realidade brasileira, assim como mais uma contribuição do presente artigo.

Tabela 5: Benefícios Estratégicos das Redes e Evidências Empíricas da Pesquisa

\begin{tabular}{|c|c|c|c|}
\hline $\begin{array}{l}\text { Conceituação } \\
\text { teórica }\end{array}$ & Variáveis observadas & Autor & Evidência Empírica \\
\hline $\begin{array}{l}\text { Aprendizagem } \\
\text { coletiva }\end{array}$ & $\begin{array}{l}\text { A interação dos atores } \\
\text { e partilha de } \\
\text { informações e } \\
\text { habilidades. }\end{array}$ & $\begin{array}{l}\text { Human e } \\
\text { Provan } \\
\text { (1997). }\end{array}$ & $\begin{array}{l}\text { "Existe uma relação muito tênue entre } \\
\text { empresa investidora e investida (...) a troca } \\
\text { de experiências através dos contactos em } \\
\text { reuniões é freqüente" (Investida } 1 \text { e } 2 \text { ) }\end{array}$ \\
\hline $\begin{array}{l}\text { Posição estratégica } \\
\text { no mercado e } \\
\text { ênfase no processo } \\
\text { de inovação }\end{array}$ & $\begin{array}{l}\text { Liderança no custo e } \\
\text { diferenciação. } \\
\text { Busca constante para } \\
\text { inovar produtos e } \\
\text { serviços. }\end{array}$ & $\begin{array}{l}\text { Porter } \\
(1986, \\
1989) \text {. } \\
\text { Thornton } \\
(1999) .\end{array}$ & $\begin{array}{l}\text { "O nosso negócio é inovar em serviços e } \\
\text { produtos" (investida 1); "Trabalhamos para } \\
\text { inovar, mas a questão custo também é } \\
\text { extremamente relevante" (Investida 2). }\end{array}$ \\
\hline $\begin{array}{l}\text { Dificuldade em } \\
\text { operar } \\
\text { financiamentos em } \\
\text { instituições } \\
\text { privadas }\end{array}$ & $\begin{array}{l}\text { Investimentos } \\
\text { recebidos apenas dos } \\
\text { investidores. }\end{array}$ & $\begin{array}{l}\text { Gompers e } \\
\text { Lerner } \\
\text { (1998). }\end{array}$ & $\begin{array}{l}\text { "A investidora possui maior conhecimento } \\
\text { dos possíveis canais para captação de } \\
\text { recursos" (Investida } 1 \text { e } 2 \text { ) }\end{array}$ \\
\hline $\begin{array}{l}\text { Investidor ganha } \\
\text { experiência ao } \\
\text { manter um contato } \\
\text { intrínseco com o } \\
\text { aportado }\end{array}$ & $\begin{array}{l}\text { O investidor mantém } \\
\text { contacto assíduo com } \\
\text { aportado, através de } \\
\text { visitas, e-mails, } \\
\text { telefonemas e reuniões. }\end{array}$ & $\begin{array}{l}\text { Sorenson e } \\
\text { Toby } \\
(2001)\end{array}$ & $\begin{array}{c}\text { "O investidor fica totalmente a par de nosso } \\
\text { negócio, já que ele é um dos maiores } \\
\text { interessados (...) sabe o que acontece na } \\
\text { empresa investida, através das reuniões e } \\
\text { relatórios" (investida } 1 \text { e } 2 \text { ). }\end{array}$ \\
\hline
\end{tabular}

Fonte: desenvolvido pelos autores. 


\section{CONCLUSÕES}

O presente trabalho teve como objetivo apresentar um entendimento das vantagens para PME's advindas da união em redes de cooperação do tipo venture capital, à luz do conceito teórico de redes de cooperação. Uma vez apresentada a revisão bibliográfica, buscou-se, por meio de uma pesquisa exploratória, trabalhar os conceitos apresentados e verificar a aplicação destes em um contexto específico: o de redes de venture capital.

A amostra das empresas entrevistadas foi escolhida por conveniência, o que demonstra uma das limitações do estudo, embora este procure contribuir com a literatura existente sobre o tema. A escolha das empresas foi feita tendo em vista a abertura dada pela empresa investidora para obtenção de dados e pelo tempo disponibilizado para as entrevistas. As duas companhias que receberam investimentos e que, por sua vez, tiveram seus diretores executivos entrevistados foram indicadas pela própria empresa investidora.

Através deste estudo exploratório pôde-se verificar algumas peculiaridades sobre as vantagens obtidas com a união em redes de venture capital. Inicialmente, pode-se concluir que empreendedores em busca de capital para o desenvolvimento de seus negócios avaliam, em um primeiro momento, o custo do capital, unicamente.

A partir do momento em que uma relação societária é estabelecida entre um empreendedor e um investidor de risco, as vantagens de tal união começam a aparecer conforme os desafios surgem e o dinheiro é investido. Basicamente, as vantagens obtidas por uma PME's, ao engajar-se em uma rede de cooperação de venture capital, dentro da visão da Investidora são: (i) a obtenção de visão estratégica do negócio, via definição de objetivos e planejamento de médio e longo prazo; (ii) ganho de visão de retorno sobre capital investido; (iii) experiência de outras empresas investidas que fazem parte do portfólio da Investidora; (iv) expertise para acesso a demais linhas de financiamento; e (v) apresentação e inserção de novas ferramentas administrativas, para viabilizar melhoria e maior controle sobre processos produtivos, gestão e formação de pessoas, financeiro, entre outros.

As vantagens citadas acima corroboram o fato de os profissionais da Investidora considerarem que a união entre Investidora e Empresa Investida 1 ou 2 seria um tipo de rede, podendo ser denominada como uma rede de cooperação.

Quando analisadas as informações obtidas a partir das entrevistas realizadas com Empreendedor 1 e Empreendedor 2, verifica-se uma concordância com relação às vantagens obtidas por meio da união em rede de cooperação de venture capital, com destaque para o fato de ser estabelecido considerável nível de confiança e transparência entre as empresas investidas, na ocorrência de rodadas de negociações ou troca de experiências.

Os resultados demonstram que a adesão de empresas a este tipo de rede se dá, inicialmente, em função do custo de capital. Posteriormente, há o reconhecimento de outras vantagens, como a possibilidade de maiores trocas de informações, a melhoria em processos empresariais (produtivos, gestão e formação de pessoas e financeiro), a aquisição de expertise para obtenção de outras linhas de financiamento e uma maior aprendizagem sobre o processo de governança. Conclui-se que a literatura sobre as vantagens da união de empresas em rede aplica-se às venture capitals, apesar de poucos estudos no Brasil abordarem este tipo de união. Sugere-se, assim, o aprimoramento dos conceitos e vantagens deste tipo de rede para o aprofundamento do tema na academia.

Artigo recebido em 05.07.2007. Aprovado em 05.09.2008. 


\section{REFERÊNCIAS BIBLIOGRÁFICAS}

Associação Brasileira de Capital de Risco \& Thompson Venture Economics. (2006). [Pesquisa $\mathrm{ABCR} / \mathrm{Thomson}-4^{\mathrm{a}}$ etapa. A pesquisa detalha o comportamento da indústria de capital de risco no Brasil no segundo semestre de 2003.] Recuperado em 05 Abril, 2006, de http://www.capitalderisco.gov.br/vcn/abcr/pesquisa_04.pdf

Balestrin, A., \& Vargas, L. M. (2003a, maio). A dimensão estratégica das redes horizontais de PMES: teorização e evidências. Anais do Encontro de Estudos em Estratégia, Curitiba, PR, Brasil, 1.

Balestrin, A., \& Vargas, L. M. (2003b, setembro). Redes horizontais de cooperação como estrutura favorável ao desenvolvimento das PMEs. Anais do Encontro Nacional da Associação Nacional de Pós-Graduação e Pesquisa em Administração, Atibaia, SP, Brasil, 27.

Balestrin, A., \& Vargas, L. M. (2004, setembro). A complementaridade de conhecimentos nos processos de inovação. Anais do Encontro Nacional da Associação Nacional de PósGraduação e Pesquisa em Administração, Curitiba, PR, Brasil, 28.

Balestro, M. V., Antunes, J. A. V., Jr, Lopes, M. C, \& Pellegrin, I. (2004). A experiência da Rede Petro-RS: uma estratégia para o desenvolvimento das capacidades dinâmicas. Revista de Administração Contemporânea, 8(Edição Especial), 181-202.

Bottazzi, L., \& Rin, M. (2002). Venture capital in Europe and the financing of innovative companies. Economic Policy, 17(34), 229-270.

Bygrave, W. D., \& Timmons, J. A. (1992). Venture capital at the crossroads. Harvard: Harvard University Press.

Casarotto, N., Filho, \& Pires, L. H. (1999). Redes de pequenas e médias empresas e desenvolvimento local: estratégias para a conquista da competitividade global com a base na experiência italiana. São Paulo: Atlas.

Deloitte, T. T. (2002). As empresas que mais crescem no Brasil. Rio de Janeiro: Deloitte.

Diário Popular. (2005, novembro 19). Rio Grande tecnológico. Recuperado em 31 maio, 2008, de http://www.diariopopular.com.br/19_11_05/artigo.html

Ebers, M. (1997). The formation of inter-organizational networks. Oxford: Oxford University Press.

Fachinelli, A. C., Marcon, C., \& Moinet, N. (2001, março 18). A prática de gestão de redes: uma necessidade estratégica da sociedade da informação. Sociedade da informação: inclusão e exclusão. Com Ciência Revista Eletrônica de Jornalismo Científico. Recuperado em 02 agosto, 2005, de http://www.comciencia.br/reportagens/socinfo/info14.htm

Fayard, P. (2000). O jogo da interação. Caxias do Sul: Educs.

Gompers, P. A., \& Lerner, J. (1998, August). What drives venture capital fundraising? Research \& Ideas [Working papers Series]. Harvard Business School, Recuperado em 4 agosto, 2005, de http://www.hbs.edu/research/facpubs/workingpapers/papers2/9899/99-079.pdf

Gompers, P. A., \& Lerner, J. (2001). The venture capital revolution. Journal of Economic Perspectives, 15(2), 154-168.

Gorini, A. P. F. (1998). Panorama do setor moveleiro no Brasil, com ênfase na competitividade externa a partir do desenvolvimento da cadeia industrial de produtos de sólidos de madeira. BNDES Setorial, 8, 3-58. 
Gorman, M., \& Sahlman, W. A. (1989). What do venture capitalists do? Journal of Business Venturing, 4(4), 231-248.

Grandori, A., \& Soda, G. (1995). Inter-Firm networks: antecedents, mechanisms and forms. Organization Studies, 16(2), 183-214.

Gulati, R., Nohria, N., \& Zaheer, A. (2000). Strategic networks. Strategic Management Journal, 21(3), 203-215.

Hair, J. F., Babin, B., Money, A. H., \& Samouel, P. (2005). Fundamentos de métodos de pesquisa em administração. Porto Alegre: Bookman.

Human, S. E., \& Provan, K. G. (1997). An emergent theory of structure and outcomes in small-firm strategic manufacturing network. Academy of Management Journal, 40(2), 368-403.

Jarillo, J. C. (1988). On strategic networks. Strategic Management Journal, 9(1), 31-41.

Leicht, K. T., \& Jenkins, J. C. (1998). Political resources and direct state intervention: the adoption of public venture capital programs in the American States. Social Forces, 76(4), 1323-1345.

Leon, M. E. (1998). Uma análise de redes de cooperação das pequenas e médias empresas do setor das telecomunicações. Dissertação de mestrado, Universidade de São Paulo, São Paulo, SP, Brasil.

Marcon, C., \& Moinet, N. (2001). Estratégia-rede. Caxias do Sul: EDUCS.

Oppenheim, A. N. (1994). Questionnaire design, interviewing and attitude measurement. Londres: Pinter Pub. Ltd.

Paiva, F. G., Jr., \& Barbosa, F. V. (2001, setembro). Redes organizacionais no sistema de cluster: reflexões sobre sua posição estratégica na busca de oportunidades pelas pequenas e médias empresas. Anais do Encontro Nacional da Associação Nacional de Pós-Graduação e Pesquisa em Administração, Campinas, SP, Brasil, 25.

Pandey, I. M., Nair, R., Varshney, V., Awasthi, D., Mehta, K., Rewari, R., \& Ramachandran, K. (2003). Entrepreneurship and venture capital. Vikalpa: The Journal of Decision Makers, 28(1), 99-112.

Porter, M. E. (1986). Estratégia competitiva: instrumentos para análise da indústria e da concorrência (7a ed.). Rio de Janeiro: Campus.

Porter, M. E. (1989). Vantagem competitiva (13a ed.). Rio de Janeiro: Campus.

Powell, W. (1990). Neither market nor hierarchy network forms of organization. Research in Organizational Behavior, 12, 295-336.

Ribault, M., Martinet, B., \& Lebidois, D. (1995). A gestão das tecnologias [Coleção gestão \& inovação]. Lisboa: Publicações Dom Quixote.

Sagari, S., \& Guidotti, G. (1992). Venture capital: lessons from the development world for the developing markets. [Discussion Paper $\mathrm{N}^{\mathrm{o}}$ 13]. International Finance Corporation, Washington, USA.

Sahlman, W. A. (1990). The structure and governance of venture-capital organizations. Journal of Financial Economics, 27(2), 473-521.

Schilitt, W. K. (1997, July). Venture catalysts or vulture capitalist? Reading in venture capital. Proceedings of the Association for Investment Management and Research, Charlotesville, VA, Canada, 4.

Simantob, M., \& Lippi, R. (2003). Guia valor econômico de inovação nas empresas. Rio de Janeiro: Globo. 
Vantagens Proporcionadas às Pequenas e Médias Empresas por meio da União em Redes de

Sorenson, O. S., \& Toby E. (2001). Syndication networks and the spatial distribution of venture capital investments. American Journal of Sociology, 106(6), 1546-1588.

Thornton, P. H. (1999). The sociology of entrepreneurship. Annual Review of Sociology, 25, 19-46.

Tripodi, T., Fellin, P., \& Meyer, H. (1981). Análise da pesquisa social. Rio de Janeiro: Francisco Alves.

Universidade do Vale do Rio dos Sinos. (2008). Pólo de informática São Leopoldo - RS - Brasil. Recuperado em $31 \quad$ maio, $2008, \quad$ de http://www.unisinos.br/parceiros/poloinformatica/index.php?option=com_content\&task= view\&id=13\&ItemIt=36

Uzzi, B. (1996). The sources and consequences of embeddedness for the economic performance of organizations: the network effect. American Sociological Review, 61(4), 674-698.

Valetec. (2008). Parque Tecnológico do Vale dos Sinos. Recuperado em 31 maio, 2008, de http://www.valetec.org.br 